\title{
Effect of Activated Sludge on the Degradation of 2-Ethylhexyl 4-Methoxycinnamate and 2-Ethylhexyl 4-(Dimethylamino)Benzoate in Wastewater
}

\author{
Alicja Gackowska D - Waldemar Studziński
}

Received: 11 December 2019 / Accepted: 5 March 2020 /Published online: 28 March 2020

(C) The Author(s) 2020

\begin{abstract}
Incomplete removal of organic pollutants during wastewater treatment is one of the main routes to introduce micro-pollutants into the environment. This group of pollutants includes, among others, UV filters. Commonly used UV filters are 2-ethylhexyl 4methoxycinnamate (EHMC) and 2-ethylhexyl 4-(dimethylamino)benzoate (ODPABA). Due to the lipophilic character, these compounds can accumulate in sludge. The effects of activated sludge on the removal of EHMC and ODPABA from wastewater have been investigated in this study. It was shown that both UV filters tend to accumulate in the sludge. The concentration of UV filters in sludge increased with the increase of activated sludge dose and time of process. It was checked whether EHMC and ODPABA were transformed in activated sludge. A gas chromatograph coupled with a mass spectrometry detector (GC-MS) was used to identify products. In the case of EHMC,
\end{abstract}

Highlights
- UV filters are removed from wastewater in $90 \%$ by the sludge.
- ODPABA has much higher tendency to adsorption in sludge than
EHMC.
- EHMC and ODPABA degradation products were identified in
wastewater and sludge.

Electronic supplementary material The online version of this article (https://doi.org/10.1007/s11270-020-04516-y) contains supplementary material, which is available to authorized users.

A. Gackowska $(\bowtie) \cdot$ W. Studziński

Faculty of Chemical Technology and Engineering, UTP

University of Science and Technology, Seminaryjna 3,

85-326 Bydgoszcz, Poland

e-mail: alicja.gackowska@utp.edu.pl ethylhexyl alcohol (EHA) and the Z-EHMC isomer were identified. Methyl-4-aminobenzoic acid (MPABA) was identified as ODPABA degradation product. Elimination of EHMC and ODPABA from wastewater mainly proceeds by adsorption of these pollutants in the sludge. Filters present in wastewater and sludge undergo transformations.

Keywords EHMC - ODPABA transformation products $\cdot$ Wastewater $\cdot$ Sludge $\cdot$ HPLC UV-Vis · GC-MS

\section{Introduction}

Organic UV filters are used to protect the skin against the harmful effects of sunlight. Chemical UV filters get directly into the environment as a result of washing away from the skin, washing clothes, while practicing water sports, as well as indirectly with municipal or industrial wastewater. These compounds have been identified as impurities in wastewater (Plagellat et al. 2006; Moeder et al. 2010; Zhang et al. 2011; Tsui et al. 2014a; Ekpeghere et al. 2016), lakes (Poiger et al. 2004; Balmer et al. 2005), and rivers (Fent et al. 2010) at levels of $\mathrm{n} \mathrm{L}^{-1}$ and $\mu \mathrm{g} \mathrm{L}^{-1}$ even in tap water (Díaz-Cruz et al. 2012; da Silva et al. 2015). Because they are applied as ingredients of shampoos, creams, and other personal protection products, they are found in both urban and rural wastewater and have also been identified in industrial wastewater. Due to the much higher consumption of cosmetic products in summer, their concentration in wastewater is even 10 times higher than that in winter 
(Biel-Maeso et al. 2019). Incomplete removal of organic pollutants during wastewater treatment is one of the main routes of introducing into the environment both monitored compounds and compounds that are recognised as new pollutants (Montes-Grajales et al. 2017). New pollutants are compounds that are introduced into the environment in low concentrations, are stable or undergo transformations with formation of toxic products, and have a negative effect on living organisms. The group of these pollutants includes pharmaceuticals, drugs, some pesticides, as well as chemical UV filters. Their concentrations in reclaimed water might range from the nanogramme to microgramme per litre levels (Acuña et al. 2015; Munz et al. 2017; Tröger et al. 2018; Fagervold et al. 2019; Mackulak et al. 2019). Commonly used UV filters are EHMC and ODPABA. Applied as components of cosmetics, they get into the environment along with wastewater. It has been shown that in wastewater entering the sewage treatment plant, EHMC occurs in the concentration range of 120-1134 $\mathrm{ng} \mathrm{L}^{-1}$ (Tsui et al. 2014a; Ekpeghere et al. 2016). A significant part of EHMC was also identified in treated wastewater. Tsui et al. (2014b) showed that in $75 \%$ of the effluent samples, EHMC occurred at the level of 163-505 $\mathrm{ng} \mathrm{L}^{-1}$. The obtained results suggest that a significant part of EHMC goes along with effluents to surface waters. ODPABA was identified less frequently and at lower concentration levels. According to Gago-Ferrero et al. (2013), ODPABA is effectively removed during wastewater treatment. ODPABA was detected in influent $(<$ $121 \mathrm{ng} \mathrm{L}^{-1}$ ) and was not observed in effluent. In wastewater treatment plants, where mechanical, biological, and chemical treatment and sand filtration were applied, the effectiveness of eliminating UV filters ranged from 18 to $99 \%$ (Balmer et al. 2005; Weiss et al. 2006). In the case when only the first stage of wastewater treatment is applied, the effectiveness of removal of UV filters is 713 times lower than that after the second stage of treatment in the presence of activated sludge (Langford et al. 2015). Similar results were obtained by Tsui et al. (2014b). They identified ODPABA only in water samples taken from recreational areas. In their opinion, recreational activities would be the main sources of this compound instead of wastewater effluent discharge.

The data obtained so far indicate that UV filters as wastewater micro-pollutants are problematic due to their physicochemical properties, the possibility of bioaccumulation in the organic matrix, and wide ranges of their concentrations in wastewater depending on the latitude, season, and sampling site. Reports on the probability of accumulation of UV filters in sewage sludge arouse anxiety, due to the fact that sewage sludge is used, among others, for agricultural purposes (Weiss et al. 2006).

Ramos et al. (2016) reviewed data on the occurrence of organic UV filters in sludge. They found that the most commonly identified UV filters are benzophenones (BP-1, BP-2, and BP-3), EHMC, 3-(4' methylbenzylidene) camphor (4-MBC), and octocrylene (OC). Their content in the sludge is at very different concentration levels, which depend on the source of sewage and methods of its treatment. Langford et al. (2015) identified EHMC and OC at levels of 551-793 and 3449-12,661 $\mathrm{ng} \mathrm{g}^{-1} \mathrm{dw}$ in sludge samples taken from a mechanical-biological-chemical treatment plant, whereas Tsui et al. (2014a) determined EHMC and OC at a level below the determined limit of quantification in sludge samples obtained from the treatment plant additionally aided by UV disinfection and chlorination processes. The effects of wastewater treatment methods on the efficiency of UV filter removing from wastewater and their content in sludge were presented by Rodil et al. (2009), Gago-Ferrero et al. (2011), Negreira et al. (2011), and Liu et al. (2010). They showed that lipophilic compounds were most often identified in sludge.

According to Quality Standards Directive 2008/105/ EC (European Commission 2015), EHMC has been classified as a potential pollutant of the aquatic environment. However, based on the collected data, it has been shown that this compound in surface waters occurs at lower concentration levels than the predicted no-effect concentration (PNEC) (Loos et al. 2018). On this basis, European Commission deleted EHMC in 2018 from the Watch List of priority substances (European Commission 2018). A different stand was adopted in the case of sewage sludge. Scarce information on concentration levels and EHMC behaviour in sewage sludge prompted the Commission (EU) to take action to check whether Member States can monitor the presence of EHMC in a sediment in a credible and comparable manner (Apel et al. 2018). Therefore, monitoring of sewage sludge in this area was intensified. Generated high-quality data concerning EHMC concentration in sludge will be used to assess the risk what allow to decide whether EHMC should be re-included in the Watch List. 
Therefore, studies aimed at extending knowledge about the influence of activated sludge on the disposal of UV filters from wastewater and their accumulation in sludge can be helpful in assessing the harmfulness of this type of micro-pollutants to the environment and living organisms. In addition, it seems that knowledge about transformation of these pollutants in wastewater and sewage sludge is also important. Moreover, treated wastewater is increasingly used for irrigation of the fields and as an indirect source of drinking water in many places in the world (Michael-Kordatou et al. 2015).

Few papers describe the products of transformation of UV filters in sludge. Badia-Fabregat et al. (2012) attempted to identify 4-MBC transformation products in sludge containing ligninolytic fungi. However, GagoFerrero et al. (2011) identified two BP-3 degradation products, both exhibiting endocrine-disrupting activity (Kunz and Fent 2006). The complex composition of sludge significantly restricts identification of pollutants, especially when they occur at low concentration levels. It is even more difficult to answer the question by what mechanisms the transformation products of the studied compounds are formed. The UV filters can interact with components of the matrix and form the products in some cases more toxic than the substrates. This is confirmed by reports on the transformation of UV filters in aqueous samples under the influence of oxidising and chlorinating agents (Negreira et al. 2008; Nakajima et al. 2009; Studziński and Gackowska 2018). Therefore, the results obtained from model studies are of significant cognitive importance.

The aim of this study was to investigate the effect of activated sludge on the process of EHMC and ODPABA elimination from wastewater as well as the determination of accumulation level of the tested compounds in sludge. Moreover, wastewater and sludge were analysed for the presence of degradation products.

\section{Materials and Methods}

\subsection{Chemicals}

In our studies, the following standard samples of chemical UV filters were used: 2,4-dihydroxybenzophenone (BP-1), 2,2',4,4'-tetrahydroxybenzophenone (BP-2) (98\%), 2-hydroxy-4-methoxybenzophenone (BP-3) (98\%), 2,2'-dihydroxy-4-methoxybenzophenone (BP-
8) (98\%), 2-ethylhexyl 4-methoxycinnamate (EHMC) (98\%), 2-ethylhexyl 4-(dimethylamino)benzoate (ODPABA) (98\%), para-aminobenzoic acid (PABA) (98\%), 4-methoxycinnamate (4MCA) (Sigma-Aldrich). Methanol (99.9\%), ethyl acetate (99.7\%), and dichloromethane (98\%) (Sigma-Aldrich) were used as solvents. Extraction columns, Supelco C18 Supelclean LC-18 SPE Tube; bed wt., $0.5 \mathrm{~g}$; volume, $6 \mathrm{~mL}$.

\subsection{Sample Collection and Pre-treatment}

Samples for studies were taken from two mechanicalbiological wastewater treatment plants (nos. I and II) in the Kuyavian-Pomeranian Voivodeship area.

Wastewater treatment plant no. I consists of pretreatment stage for disposal of solid impurities and two main stages of purification, physicochemical and biological treatment, based mainly on the removal of organic pollutants, nitrification and denitrification of nitrogen compounds, and biological dephosphatation assisted by volatile fatty acids. To remove excess phosphorus, treatment plant I uses an iron salt dosing station. Sewage sludge is subjected to thermal hydrolysis resulting in biogas. (Fig. 1 Supplementary). Wastewater treatment plant II treats wastewater using mechanical and biological methods. Wastewater after mechanical treatment is directed through distribution chambers to biological reactors used to remove carbon, nitrogen, and phosphorus compounds in a common transformation system (Fig. 2 Supplementary).

All wastewater samples were collected monthly from December 2014 to January 2016. Wastewater samples were collected in dark glass bottles (1-L capacity). In order to stabilise the analytes, the samples were acidified to $\mathrm{pH}=3$. During transport to the laboratory, they were stored in a refrigerator at $4{ }^{\circ} \mathrm{C}$.

Sludge samples was collected in clean brown glass containers and shipped in refrigerated coolers to the laboratory. The sludge was characterised by the following parameters: age of sludge used, 21 days; relative volume, 560; volume index, $56.0 \mathrm{~mL} \mathrm{~L}^{-1}$; microorganisms present in the sludge, protozoa and invertebrates.

\subsection{Analytical Methodology}

The sample of wastewater was prepared by solid phase extraction (SPE) technique. For this purpose, extraction columns (Supelco C18), which were previously conditioned with $10 \mathrm{~mL}$ of dichloromethane/ethyl acetate 
mixture (1:1), were used, followed by washing with $10 \mathrm{~mL}$ of methanol and $5 \mathrm{~mL}$ of deionised water. Two hundred fifty millilitres of wastewater was passed through the prepared column. The tested analytes were extracted with $10 \mathrm{~mL}$ of dichloromethane/ethyl acetate mixture (1:1). The resulting solution was concentrated to a 1-mL prepared sample and was analysed by liquid chromatography method (HPLC). For this purpose, Shimadzu HPLC system coupled with a UV-Vis detector was applied. Separation of compounds was performed using a HPLC column (Luna $5 \mathrm{u}$ C18 (2) 100A + GraceSmart RP18 5u $(250 \times 4.60 \mathrm{~mm}+150 \times$ $4.60 \mathrm{~mm}$ ); temperature of column was $40{ }^{\circ} \mathrm{C}$ ). The injected sample volume was $25 \mu \mathrm{L}$. Mobile phase, methanol:acetonitrile:water (45:35:20). Analysis was performed at $\lambda=312 \mathrm{~nm}$.

The identification of EHMC, ODPABA, and their transformation products in wastewater and sludge samples was made using of GC-MS (gas chromatography coupled with a mass spectrometry detector, HewlettPackard 5890). Separation of the compounds was carried out on a ZB-5MS column $(30 \mathrm{~m} \times 0.25 \mathrm{~mm} \times$ $0.25 \mu \mathrm{m}$ ), and helium was used as the carrier gas. The GC column temperature was programmed from $80^{\circ} \mathrm{C}$, ramped at $10{ }^{\circ} \mathrm{C} / \mathrm{min}$ to $260{ }^{\circ} \mathrm{C}$, ramped at $5{ }^{\circ} \mathrm{C} / \mathrm{min}$ to $300{ }^{\circ} \mathrm{C}$, and helsd for $2 \mathrm{~min}$.

The GC-MS method was also used by Liu et al. (2010), Kameda et al. (2011), Román et al. (2011), and Wu et al. (2013) to identify UV filters in river water. However, Ge and Lee (2012) used the HPLC UV method to determine mainly benzophenones.

\subsection{The Model System of the Experiment}

The impact of activated sludge on the elimination of EHMC and ODPABA from wastewater was studied on a model system.

Wastewater and activated sludge samples collected in winter from treatment plant I were used for the tests. Wastewater, to which EHMC and ODPABA were added at concentration of $1.4 \cdot 10^{-4} \mathrm{~mol} \mathrm{~L}{ }^{-1}$, was introduced into a 5-L reactor. The reactor was replenished with activated sludge, so that the content of activated sludge was $5 \%, 10 \%$, and $20 \%$, respectively. The system was stirred and aerated throughout the reaction. After the specified time $(0.5 ; 4 ; 8 ; 20 ; 32 \mathrm{~h}), 250 \mathrm{~mL}$ of the sample was taken. A laboratory centrifuge was used in order to separate the sludge from wastewater (Fig. 3 Supplementary). Wastewater samples for chromatographic analysis were prepared using the SPE technique. In turn, sewage samples were dried at room temperature and then extracted with $20 \mathrm{~mL}$ of dichloromethane. The extract was concentrated on a vacuum evaporator. The UV filters and their degradation products were identified by the GC-MS method.

\section{Results and Discussion}

\subsection{Identification of UV Filters in Wastewater}

HPLC UV-Vis method allows the determination of filters at a low concentration level of ng $\mathrm{L}^{-1}$. RSD of analytes determined was in the range from 4.8 to $7.2 \%$. The recoveries of the tested UV filters were in the range of $63-114 \%$. The results are presented in Table 1.

In the next stage, studies on wastewater sampled from two biological-chemical sewage treatment plants (I and II) were conducted. Wastewater samples were prepared for analysis by SPE technique. Then, they were analysed by HPLC UV-Vis. On the basis of chromatogram obtained, it was observed that characteristic signals in the tested wastewater are present at retention times $t_{\mathrm{R}}=25.49$ and 26.78 corresponding to compounds ODPABA and EHMC (Fig. 4 Supplementary). To confirm the results, ODPABA, EHMC, and BP-3 solutions in $0.05 \mathrm{mg} \mathrm{L}^{-1}$ of methanol were added to the sewage. Wastewater prepared in this way was analysed again. The obtained data confirmed the presence of ODPABA and EHMC in wastewater from wastewater treatment plant I (Fig. 4a Supplementary). Analysis of wastewater from sewage treatment plant II was performed in an

Table 1 Main parameters of the proposed HPLC UV-Vis method for the determination of selected UV filters

\begin{tabular}{llllll}
\hline Analyte & $\begin{array}{l}\text { LOD } \\
\left(\mathrm{ng} \mathrm{L}^{-1}\right)\end{array}$ & LOQ & $r^{2}$ & $\begin{array}{l}\text { RSD } \\
(\%)\end{array}$ & Recovery \\
\hline BP-1 & 1.05 & 3.15 & 0.9967 & 4.8 & 64.68 \\
BP-2 & 2.3 & 6.9 & 0.9777 & 5.3 & 63.35 \\
BP-3 & 0.23 & 0.69 & 0.9985 & 5.8 & 82.49 \\
BP-8 & 1.52 & 4.56 & 0.994 & 7.2 & 78.46 \\
PABA & 2.36 & 7.08 & 0.9381 & 5.9 & 63.23 \\
ODPABA & 0.95 & 2.85 & 0.9976 & 5.6 & 69.69 \\
4MCA & 0.57 & 1.71 & 0.9833 & 6.3 & 103.21 \\
EHMC & 0.06 & 0.18 & 0.9963 & 6.9 & 114.37 \\
\hline
\end{tabular}


analogous manner. However, in this case, the compound BP-3 was also identified beside ODPABA and EHMC (Fig. 5 and 5a Supplementary). BP-1, BP-2, and BP-8 were not identified in the samples studies, both from the 1 st and the 2 nd wastewater treatment plants.

Studies on wastewater sampled in different seasons prove seasonality of their occurrence because the highest concentrations are observed in the summer when the consumption of products containing the chemical UV filters is the most intense. In winter, the tested UV filters were not identified in wastewater. The concentrations determined in wastewater samples were within the following range: BP-3 from 2.8 (spring) to 555 (summer) $\mu \mathrm{g} \mathrm{L}^{-1}$; ODPABA from 196 (spring) to 1241(summer) $\mu \mathrm{g} \mathrm{L}^{-1}$; EHMC from 234 (spring) to 1075 (summer) $\mu \mathrm{g} \mathrm{L}^{-1}$. It should be noted that in the summer time, also the share of UV radiation increases, affecting the stability of these compounds (Gaspar and Maia Campos 2006; Rodil et al. 2009). In an aqueous medium and in the presence of UV, EHMC undergoes isomerisation from $E$-EHMC to Z-EHMC forms. Additionally, the presence of oxidising and chlorinating agents contributes to the formation of products which can be significantly more toxic than the raw material itself. Studies conducted on the model systems under controlled conditions demonstrated susceptibility of EHMC and ODPABA on the action of hydrogen peroxide, sodium chlorate(I), ozone, and UV radiation (Negreira et al. 2008; Gackowska et al. 2014, 2016). In the case of ODPABA, demethylation occurs, resulting in the formation of 2-ethylhexyl 4-(methylamino)benzoate (OMPABA) among others. On the basis of data obtained from the GC-MS analysis, it was found that this product was present in wastewater. Moreover, isomer Z-EHMC was identified. However, chloroorganic product derivatives of EHMC or ODPABA were not identified (Fig. 1).

\subsection{Effect of Activated Sludge on Removal of UV Filters from Wastewater}

Compounds that are relatively stable to biological or chemical degradation can be removed from the aqueous phase by sorption on the sludge. Therefore, the next step was to investigate the effect of activated sludge on the change in EHMC and ODPABA concentrations. During the tests, the $\mathrm{pH}$ level of wastewater was monitored, which was in the $\mathrm{pH}$ range 7.3-8.4.
Studies have shown that both UV filters tend to accumulate in the sludge. Figure 2 shows the loss of ODPABA and EHMC as a function of time depending on the percentage of activated sludge in sewage.

The fastest loss of filters from sewage is observed in a reactor containing $20 \%$ of activated sludge. ODPABA and EHMC degradation, after $8 \mathrm{~h}$ of treatment, was at the level of $80 \%$ and $50 \%$, respectively, in relation to the initial value. A significantly smaller loss of filters was recorded in reactors with $5 \%$ and $10 \%$ share of activated sludge. After $32 \mathrm{~h}$ of the process, concentration of ODPABA decreased by $20 \%$ and EHMC by $50 \%$, respectively.

Due to the high lipophilicity and poor biodegradability of most UV filters, they are expected to end up in sewage sludge during wastewater treatment (GagoFerrero et al. 2011). The degree of accumulation of EHMC and ODPABA in sludge was also studied. Our research indicates that the effectiveness of EHMC and ODPABA removal depends on the dose of activated sludge. The highest degree of accumulation in the sludge was recorded in the reactor containing $20 \%$ of sludge. Taking into account the same duration of processes, ODPABA adsorbs at a considerably higher concentration than EHMC (Fig. 3).

The results confirm that elimination of priority organic and inorganic pollutants from wastewater occurs by their adsorption in sludge (Badia-Fabregat et al. 2012; Zhao et al. 2018). The ability to absorb EHMC and ODPABA in soil and sludge is also confirmed by parameters such as $\log K_{\mathrm{ow}}$ and $\log K_{\mathrm{oc}}$, determined using the EPI Suite software (EPI Suite ${ }^{\mathrm{TM}}$-Estimation Program Interface, version 4.11) (Table 1 Supplementary). Based on the calculated parameters, it was shown that the tested filters have the ability to accumulate in living tissues $\left(\log K_{\mathrm{ow}}>5\right)$ (Fig. 6 Supplementary). In addition, the value of $\log K_{\mathrm{oc}}$ parameter classifies EHMC as a strong sorption compound for soil/sludge and ODPABA as a substance with moderate capacity (Table 2 Supplementary). The lipophilic nature of EHMC indicates that it will deposit on solid organic particles. The presence of iron chloride also contributes to the increase in the removal efficiency of hydrophobic organic compounds, which accelerates the process of aggregation of particles during coagulation and wastewater sedimentation (Carballa et al. 2005). However, much better results are achieved in processes involving activated sludge (>90\%) (Kupper et al. 2006). Similar effects are obtained in the case of the reverse osmosis process. Reverse osmosis was found to 
Abundance a)

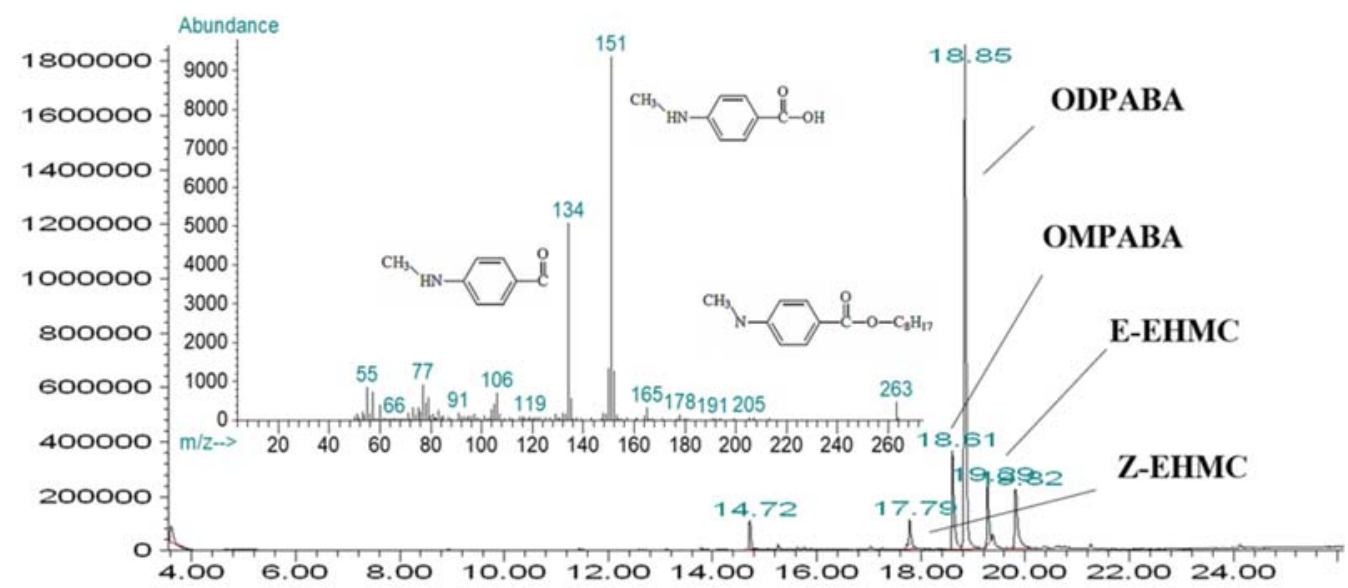

Time->

Fig. 1 GC-MS chromatogram for wastewater from sewage treatment plant I. a Mass spectrum of octyl para-aminobenzoic acid (OMPABA)

Fig. 2 a, b Loss of ODPABA and EHMC from wastewater, over time, depending on the share of sludge in reactor. Green line indicates $5 \%$ of sludge, red line indicates $10 \%$ of sludge, and blue line indicates $20 \%$ of sludge a) ODPABA

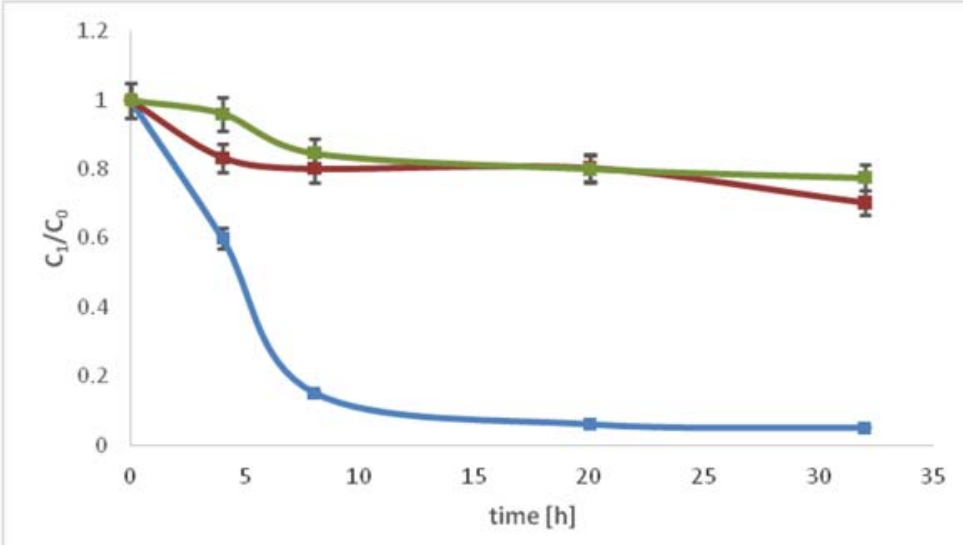

b) EHMC

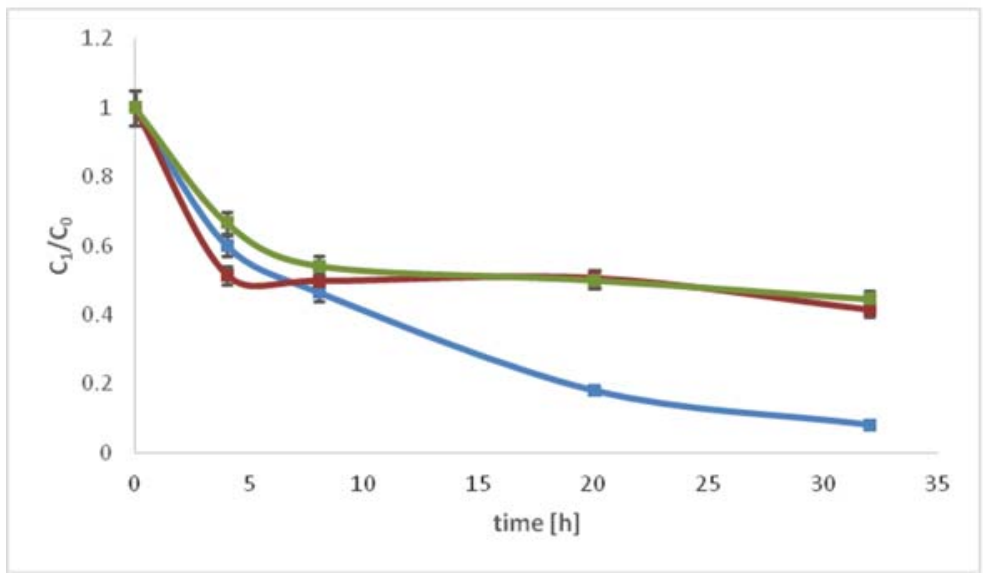


Fig. 3 a, b Accumulation of ODPABA and EHMC in sludge, over time, depending on the share of sludge in reactor. Green line indicates $5 \%$ of sludge, red line indicates $10 \%$ of sludge, and blue line indicates $20 \%$ of sludge a) ODPABA

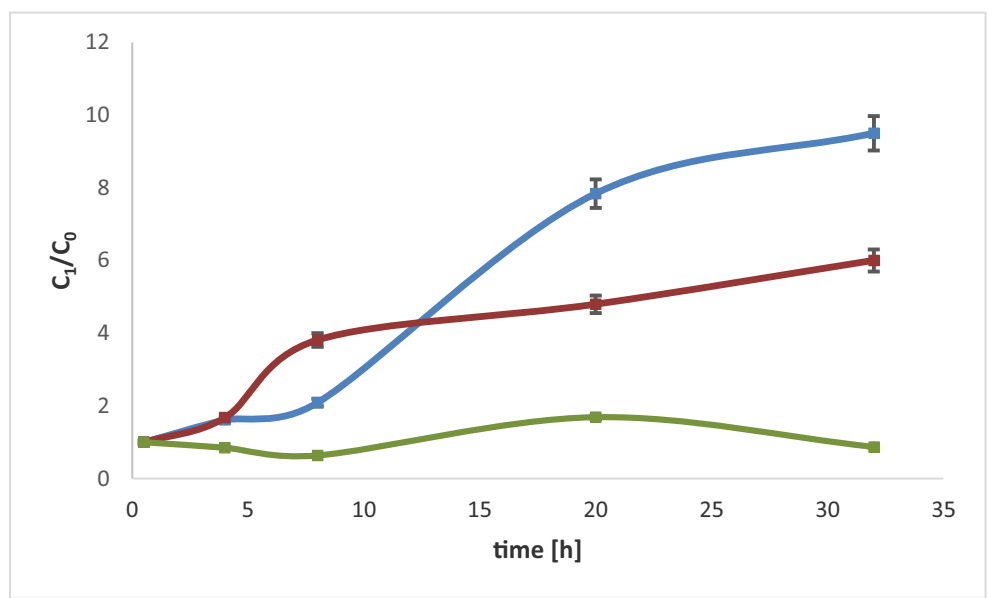

b) $\mathrm{EHMC}$

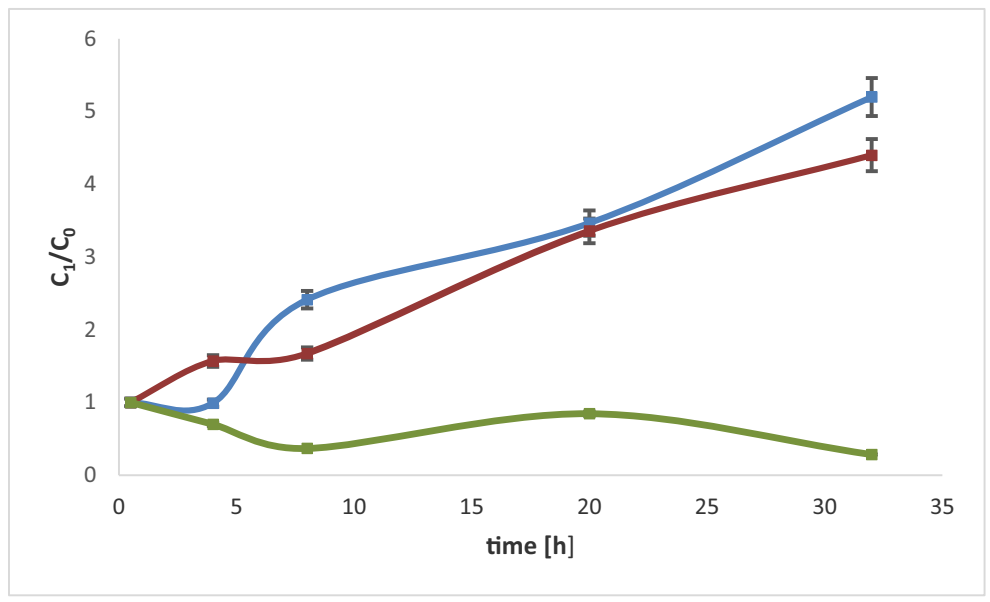

effectively eliminate UV filters from effluent ( $>99 \%$ removal) (Tsui et al. 2014a). However, the costs of this process are very high. In the process of wastewater treatment using activated sludge, besides the adsorption process, biodegradation of pollutants also takes place (De la Cruz et al. 2012). The effect of activated sludge on the degree of removal of UV filters from wastewater was also confirmed by indicators determining the removal of EHMC and ODPABA from wastewater as a result of the adsorption on sludge and biodegradation in wastewater treatment plant. On the basis of the calculated indices, it can be assumed that elimination of EHMC and ODPABA from wastewater, in traditional wastewater treatment plants, mainly takes place by adsorption of these pollutants in the sludge (90\%) and to a small extent by biodegradation (Fig. 4).
According to many researchers, the sorption process is crucial in removing these pollutants from wastewater. However, the effectiveness of this process is in a wide range from 30 to $90 \%$. Such a large spread can be explained by the presence of other pollutants in wastewater, physicochemical properties of the pollutants themselves, activated sludge age, oxidation-reduction conditions, temperature, season, or organisation of the individual biological stages (Fent et al. 2010; Hai et al. 2011; De la Cruz et al. 2012; Gago-Ferrero et al. 2013; Mackul'ak et al. 2015; Zhao et al. 2018). In addition, the existing data confirm presence of EHMC in both wastewater and sewage sludge. ODPABA was identified mainly in wastewater, while it occurred at trace concentration levels or was absent in sludge (Nieto et al. 2009; Gago-Ferrero et al. 2011; Tsui et al. 2015). According to 
Fig. 4 Degree of removal of UV filters from wastewater. Blue indicates a result of adsorption in sludge, and green indicates a result of biodegradation

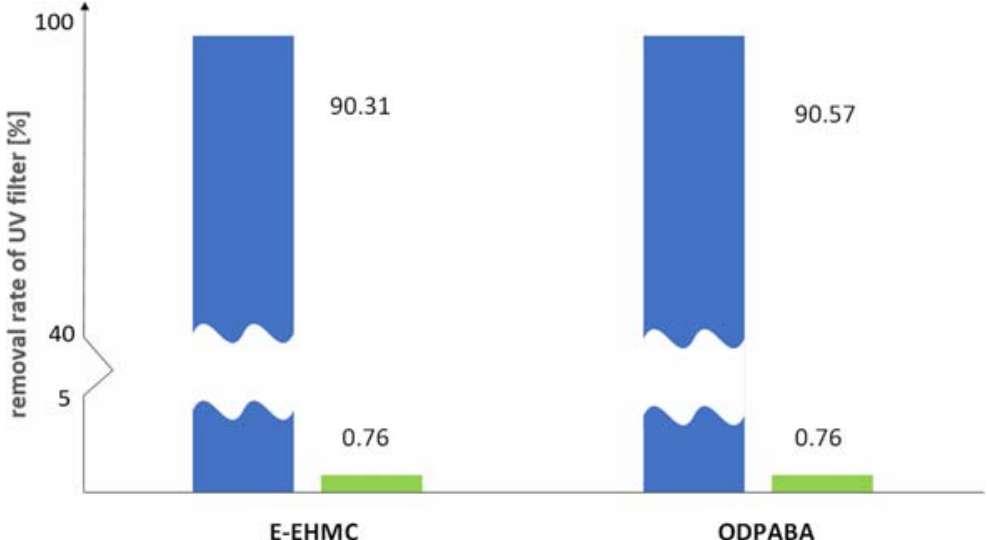

of wastewater and sludge was performed in order to identify the degradation products of the tested UV filters. Municipal wastewater collected in winter from wastewater treatment plant I was used for the study. First, the initial material, raw wastewater, and activated sludge were subjected to GC-MS analysis. No UV filters were detected in both wastewater and sludge. The absence of UV filters can be explained by the fact that wastewater and sludge samples were collected in the winter period, when UV filter consumption is low (Fig. 5).

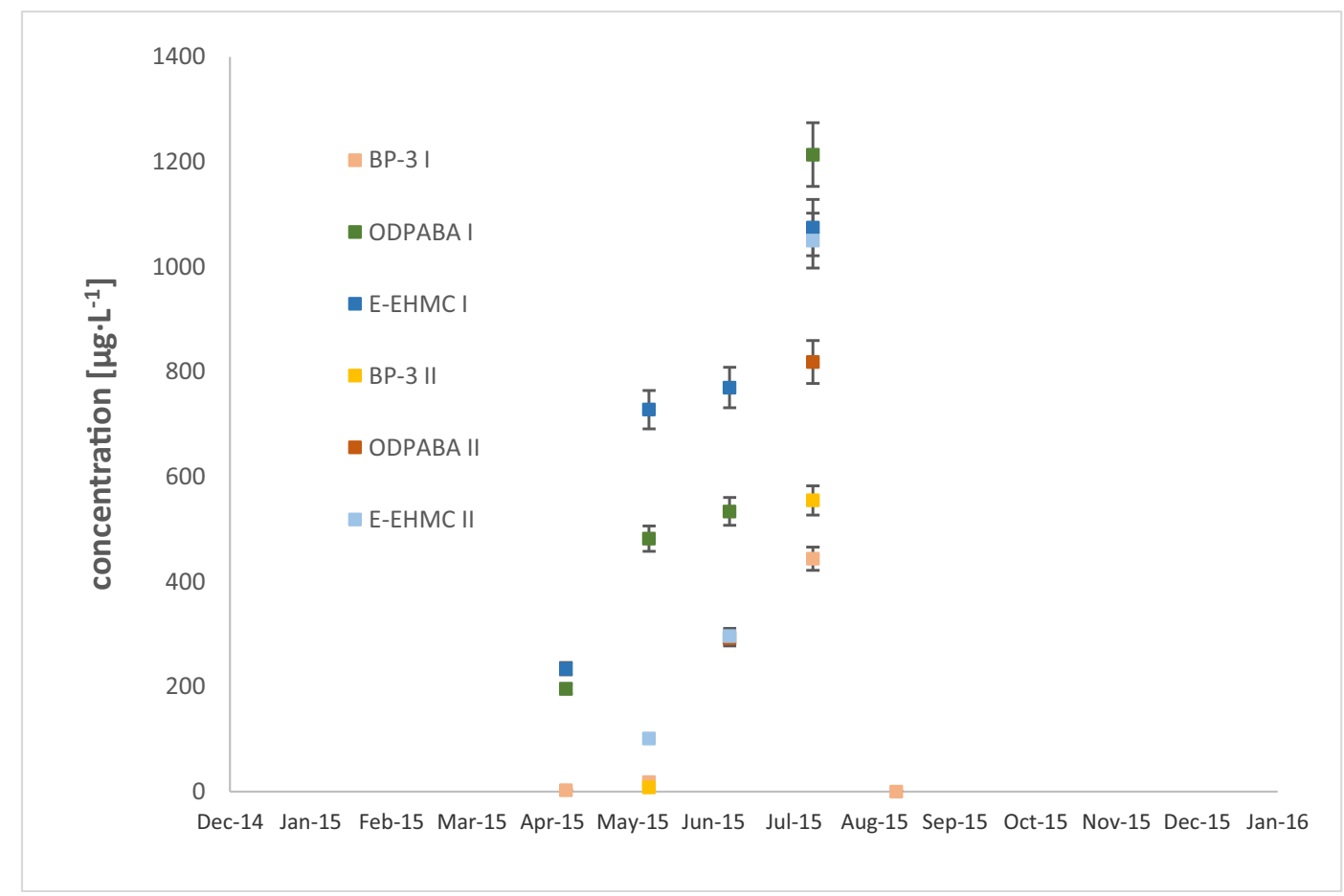

Fig. 5 Concentrations of UV filters in wastewater collected from sewage treatment plant I and sewage treatment plant II 
Abundance

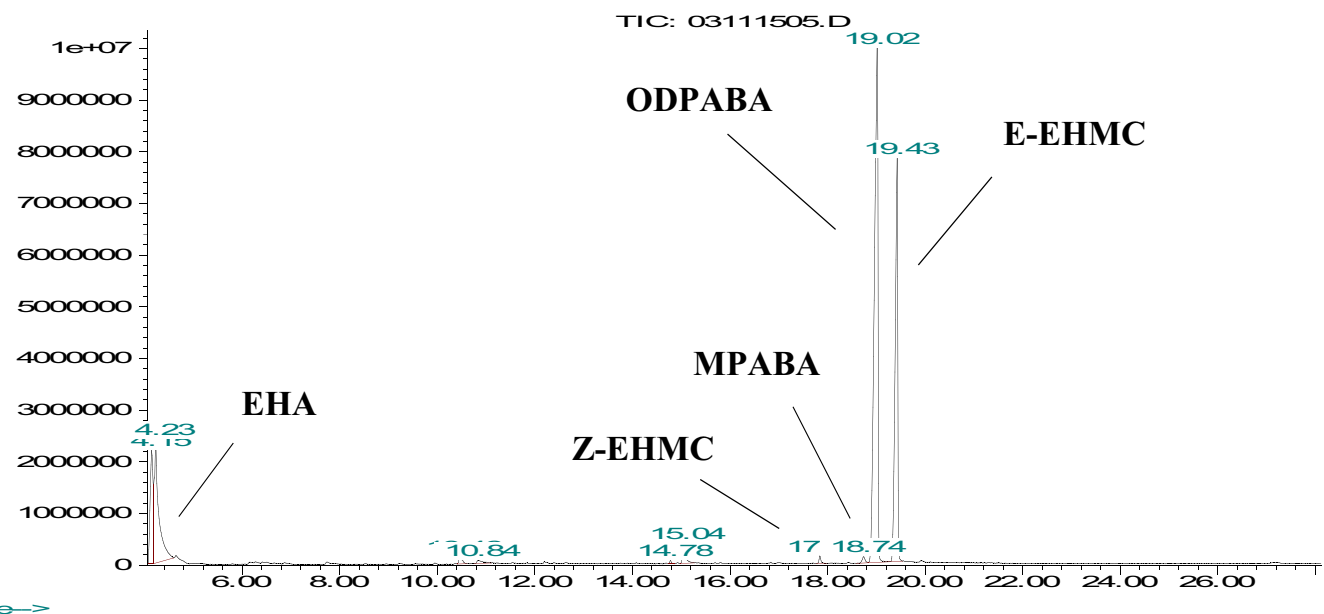

Fig. 6 Chromatogram of wastewater extract with $20 \%$ of activated sludge

Therefore, EHMC and ODPABA were added to wastewater. Wastewater prepared in this way was introduced into the reactor, activated sludge was added, and then the system was aerated. Already after $30 \mathrm{~min}$ of the process, regardless of the percentage of activated sludge, EHMC and ODPABA distribution between liquid phase (wastewater) and solid phase (sludge) was observed in the reactor. Two degradation products of EHMC, i.e., EHA and Z-EHMC isomer, as well as MPABA as the degradation product of ODPABA were identified in wastewater by GC-MS method (Fig. 6). Most EHMC and ODPABA degradation products were identified in wastewater containing $20 \%$ of activated sludge. In the case of activated sludge, in addition to EHMC, ODPABA and MPABA were found (Fig. 7). The mass spectra of the identified products are presented in Supplementary in Figs. 7-9. However, EHA was not identified (Fig. 7). It may be due to the fact that it is a hydrophilic compound ( $\log K_{\text {ow }} 2.73$ ), which migrates to water and is not absorbed in the soil, $\log K_{\mathrm{oc}} 1.415$. The mentioned products are also formed under the influence of oxidising and chlorinating agents (Gackowska et al. 2016, 2018).

\section{Summary}

The different concentration levels of UV filters removed from wastewater suggest that the mechanism of wastewater treatment used can be important when assessing

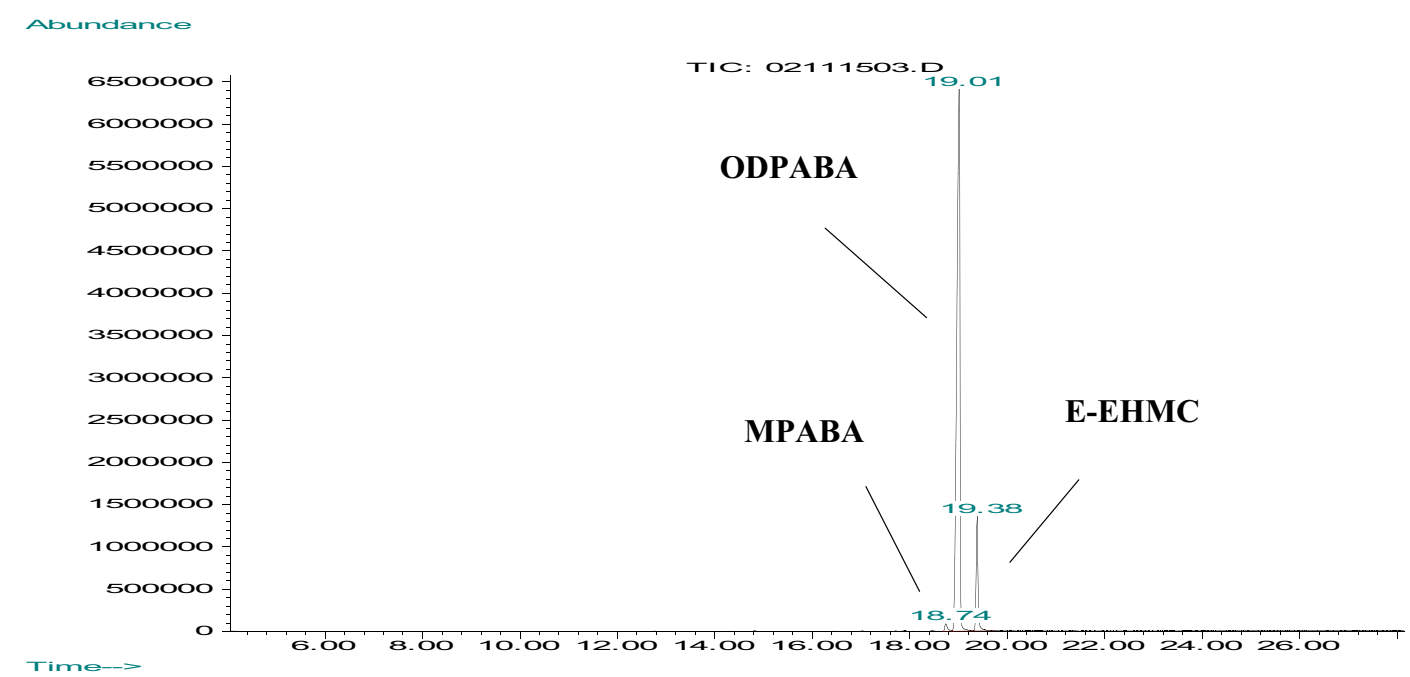

Fig. 7 Chromatogram of activated sludge extract 
the effectiveness of elimination of non-biodegradable micro-pollutants. It has been confirmed that traditional methods of wastewater treatment allow partial removal of UV filters. Due to the lipophilic properties of EHMC and ODPABA, these compounds tend to accumulate in sludge. The elimination of EHMC and ODPABA from wastewater mainly proceeds through adsorption of these pollutants in the sludge. Concentration of UV filters in sludge increased with increase of the activated sludge dose and duration of the process. UV filters present in wastewater and sludge undergo transformations. In both matrices, degradation products of the tested compounds were identified. In the case of EHMC, these are the $Z$ EHMC isomer and EHA while ODPABA is demethylated to form MPABA. This fact stresses the need for identifying not only the parent compounds but also their transformation products. Moreover, the obtained results suggest the necessity of introducing new solutions of wastewater treatment, which will intensify the process of elimination of micro-pollutants from wastewater and increase the efficiency of degradation of these pollutants in sludge. Application of the advanced oxidation processes of organic pollutants may be a necessary activity in achieving satisfactory effects of EHMC and ODPABA degradation.

Open Access This article is licensed under a Creative Commons Attribution 4.0 International License, which permits use, sharing, adaptation, distribution and reproduction in any medium or format, as long as you give appropriate credit to the original author(s) and the source, provide a link to the Creative Commons licence, and indicate if changes were made. The images or other third party material in this article are included in the article's Creative Commons licence, unless indicated otherwise in a credit line to the material. If material is not included in the article's Creative Commons licence and your intended use is not permitted by statutory regulation or exceeds the permitted use, you will need to obtain permission directly from the copyright holder. To view a copy of this licence, visit http://creativecommons.org/licenses/by/4.0/.

\section{References}

Acuña, V., von Schiller, D., García-Galán, M. J., RodríguezMozaz, S., Corominas, L., \& Petrovic, M. (2015). Occurrence and in-stream attenuation of wastewater-derived pharmaceuticals in Iberian rivers. Science of the Total Environment, 503-504, 133-141. https://doi.org/10.1016/j. scitotenv.2014.05.067.

Apel, C., Joerss, H., \& Ebinghaus, R. (2018). Environmental occurrence and hazard of organic UV stabilizers and UV filters in the sediment of European North and Baltic Seas. Chemosphere, 212, 254-261. https://doi.org/10.1016/j. chemosphere.2018.08.105.

Badia-Fabregat, M., Rodríguez-Rodríguez, C. E., Gago-Ferrero, P., Olivares, A., Piña, B., Díaz-Cruz, M. S., Vicent, T., Barceló, D., \& Caminal, G. (2012). Degradation of UV filters in sewage sludge and $4-\mathrm{MBC}$ in liquid medium by the ligninolytic fungus Trametes versicolor. Journal of Environmental Management, 104, 114-120. https://doi. org/10.1016/j.jenvman.2012.03.039.

Balmer, M. E., Buser, H. R., Müller, M. D., \& Poiger, T. (2005). Occurrence of some organic UV filters in wastewater, in surface waters, and in fish from Swiss Lakes. Environmental Science \& Technology, 39, 953-962. https://doi.org/10.1021/es040055r.

Biel-Maeso, M., Corada-Fernández, C., \& Lara-Martín, P. A. (2019). Removal of personal care products (PCPs) in wastewater and sludge treatment and their occurrence in receiving soils. Water Research, 150, 129-139. https://doi.org/10.1016 j.watres.2018.11.045.

Carballa, M., Omil, F., \& Lema, J. M. (2005). Removal of cosmetic ingredients and pharmaceuticals in sewage primary treatment. Water Research, 39, 4790-4796. https://doi. org/10.1016/j.watres.2005.09.018.

da Silva, C. P., Emídio, E. S., \& de Marchi, M. R. R. (2015). The occurrence of UV filters in natural and drinking water in São Paulo State (Brazil). Environmental Science and Pollution Research, 22, 19706-19715. https://doi.org/10.1007/s11356015-5174-3.

De la Cruz, N., Giménez, J., Esplugas, S., Grandjean, D., de Alencastro, L. F., \& Pulgarín, C. (2012). Degradation of 32 emergent contaminants by UV and neutral photo-Fenton in domestic wastewater effluent previously treated by activated sludge. Water Research, 46, 1947-1957. https://doi. org/10.1016/j.watres.2012.01.014.

Díaz-Cruz, M. S., Gago-Ferrero, P., Liorca, M., \& Barceló, D. (2012). Analysis of UV filters in tap water and other clean waters in Spain. Analytical and Bioanalytical Chemistry, 402, 2325-2333. https://doi.org/10.1007/s00216-011-55608.

Ekpeghere, K. I., Kim, U.-J., O, S.-H., Kim, H.-Y., \& Oh, J.-E. (2016). Distribution and seasonal occurrence of UV filters in rivers and wastewater treatment plants in Korea. Science of the Total Environment, 542, 121-128. https://doi. org/10.1016/j.scitotenv.2015.10.033.

European Commission (2015) Commission Implementing Decision (EU) 2015/495 of 20 March 2015 establishing a watch list of substances for Union-wide monitoring in the field of water policy pursuant to Directive 2008/105/EC of the European Parliament and of the Council.

European Commission (2018) Commission Implementing Decision (EU) 2018/840 of 5 June 2018 establishing a watch list of substances for Union-wide monitoring in the field of water policy pursuant to Directive 2008/105/EC of the European Parliament and of the Council and repealing Commission Implementing Decision (EU) 2015/495.

Fagervold, S. K., Rodrigues, A. S., Rohée, C., Roe, R., Bourrain, M., Stien, D., \& Lebaron, P. (2019). Occurrence and environmental distribution of $5 \mathrm{UV}$ filters during the summer season in different water bodies. Water, Air, \& Soil 
Pollution, 230, 172. https://doi.org/10.1007/s11270-0194217-7.

Fent, K., Zenker, A., \& Rapp, M. (2010). Widespread occurrence of estrogenic UV-filters in aquatic ecosystems in Switzerland. Environmental Pollution, 158, 1817-1824. https://doi. org/10.1016/j.envpol.2009.11.005.

Gackowska, A., Przybyłek, M., Studzínski, W., \& Gaca, J. (2014). Experimental and theoretical studies on the photodegradation of 2-ethylhexyl 4-methoxycinnamate in the presence of reactive oxygen and chlorine species. Central European Journal of Chemistry, 12, 612-623. https://doi.org/10.2478/s11532014-0522-6.

Gackowska, A., Studziński, W., Gaca, J., \& Przybyłek, M. (2016). Formation of chlorinated breakdown products during degradation of sunscreen agent, 2-ethylhexyl-4methoxycinnamate in the presence of sodium hypochlorite. Environmental Science and Pollution Research, 23, 18861897. https://doi.org/10.1007/s11356-015-5444-0.

Gackowska, A., Studziński, W., Kudlek, E., Dudziak, M., \& Gaca, J. (2018). Estimation of physicochemical properties of 2ethylhexyl-4-methoxycinnamate (EHMC) degradation products and their toxicological evaluation. Environmental Science and Pollution Research, 25, 16037-16049. https://doi.org/10.1007/s11356-018-1796-6.

Gago-Ferrero, P., Díaz-Cruz, M. S., \& Barceló, D. (2011). Occurrence of multiclass UV filters in treated sewage sludge from wastewater treatment plants. Chemosphere, 84, 11581165. https://doi.org/10.1016/j.chemosphere.2011.04.003.

Gago-Ferrero, P., Mastroiannia, N., Díaz-Cruz, M. S., \& Barceló, D. (2013). Fully automated determination of nine ultraviolet filters and transformation products in natural waters and wastewaters by on-line solid phase extraction-liquid chromatography-tandem mass spectrometry. The Journal of Chromatography A, 1294, 106-116. https://doi.org/10.1016 jj.chroma.2013.04.037.

Gaspar, L. R., \& Maia Campos, P. M. B. G. (2006). Evaluation of the photostability of different UV filter combinations in a sunscreen. International Journal of Pharmaceutics, 307, 123-128. https://doi.org/10.1016/j.ijpharm.2005.08.029.

Ge, D., \& Lee, H. K. (2012). A new 1-hexyl-3-methylimidazolium tris (pentafluoroethyl) trifluorophosphate ionic liquid based ultrasound-assisted emulsification microextraction for the determination of organic ultraviolet filters in environmental water samples. Journal of Chromatography A, 1251, 27-32. https://doi.org/10.1016/j.chroma.2012.06.048.

Hai, F. I., Tessmer, K., Nguyen, L. N., Kang, J., Price, W. E., \& Nghiem, L. D. (2011). Removal of micropollutants by membrane bioreactor under temperature variation. The Journal of Membrane Science, 383, 144-151. https://doi.org/10.1016/j. memsci.2011.08.047.

Kameda, Y., Kimura, K., \& Miyazaki, M. (2011). Occurrence and profiles of organic sunblocking agents in surface waters and sediments in Japanese rivers and lakes. Environmental Pollution, 159, 1570-1576.

Kunz, P. Y., \& Fent, K. (2006). Multiple hormonal activities of UV filters and comparison of in vivo and in vitro estrogenic activity of ethyl-4-aminobenzoate in fish. Aquatic Toxicology, 79, 305-324. https://doi.org/10.1016/j. aquatox.2006.06.016.

Kupper, T., Plagellat, C., Brändli, R. C., de Alencastro, L. F., Grandjean, D., \& Tarradellas, J. (2006). Fate and removal of polycyclic musks, UV filters and biocides during wastewater treatment. Water Research, 40, 2603-2612. https://doi. org/10.1016/j.watres.2006.04.012.

Langford, K. H., Reid, M. J., Fjeld, E., Øxnevad, S., \& Thomas, K. V. (2015). Environmental occurrence and risk of organic UV filters and stabilizers inmultiple matrices in Norway. Environment International, 80, 1-7. https://doi.org/10.1016 /j.envint.2015.03.012.

Liu, H., Liu, L., Xiong, Y., Yang, X., \& Luan, T. (2010). Simultaneous determination of UV filters and polycyclic musks in aqueous samples by solid-phase microextraction and gas chromatography-mass spectrometry. Journal of Chromatography A., 1217, 6747-6753. https://doi. org/10.1016/j.chroma.2010.06.004.

Loos, R., Marinov, D., Sanseverino, I., Napierska, D., Lettieri, T. (2018) Review of the 1st Watch List under the Water Framework Directive and recommendations for the 2nd Watch List. European Commission JRC Technical Reports.

Mackul'ak, T., Nagyová, K., Fáberová, M., Grabic, R., Koba, O., Gál, M., \& Birošová, L. (2015). Utilization of Fenton-like reaction for antibiotics and resistant bacteria elimination in different parts of WWTP. Environmental Toxicology and Pharmacology, 40, 492-497. https://doi.org/10.1016/j. etap.2015.07.002.

Mackul'ak, T., Cernanský, S., Fehér, M., Birošová, L., \& Gál, M. (2019). Pharmaceuticals, drugs, and resistant microorganisms - environmental impact on population health. Current Opinion in Environmental Science \& Health, 9, 40-48. https://doi.org/10.1016/j.coesh.2019.04.002.

Michael-Kordatou, I., Michael, C., Duan, X., He, X., Dionysiou, D. D., Mills, M. A., \& Fatta-Kassinos, D. (2015). Dissolved effluent organic matter: characteristics and potential implications in wastewater treatment and reuse applications. Water Research, 77, 213-248. https://doi.org/10.1016/j. watres.2015.03.011.

Moeder, M., Schrader, S., Winkler, U., \& Rodil, R. (2010). At-line microextraction by packed sorbent-gas chromatographymass spectrometry for the determination of UV filter and polycyclic musk compounds in water samples. Journal of Chromatography A, 1217, 2925-2932. https://doi. org/10.1016/j.chroma.2010.02.057.

Montes-Grajales, D., Fennix-Agudelo, M., \& Miranda-Castro, W. (2017). Occurrence of personal care products as emerging chemicals of concern in water resources: a review. Science of the Total Environment, 595, 601-614. https://doi. org/10.1016/j.scitotenv.

Munz, N. A., Burdon, F. J., de Zwart, D., Junghans, M., Melo, L., Reyes, M., Schönenberger, U., Singer, H. P., Spycher, B., Hollender, J., \& Stamm, C. (2017). Pesticides drive risk of micropollutants in wastewater-impacted streams during low flow conditions. Water Research, 110, 366-377. https://doi. org/10.1016/j.watres.2016.11.001.

Nakajima, M., Kawakami, T., Niino, T., Takahashi, Y., \& Onodera, S. (2009). Aquatic fate of sunscreen agents octyl4-methoxycinnamate and octyl-4-dimethylaminobenzoate in model swimming pools and the mutagenic assays of their chlorination byproducts. Journal of Health Sciences, 55, 363-372. https://doi.org/10.1248/jhs.55.363.

Negreira, N., Canosa, P., Rodríguez, I., Ramil, M., Rubíand, E., \& Cela, R. (2008). Study of some UV filters stability in chlorinated water and identification of halogenated by-products by 
gas chromatography-mass spectrometry. Journal of Chromatography A, 1178, 206-214. https://doi.org/10.1016 /j.chroma.2007.11.057.

Negreira, N., Rodríguez, I., Rubí, E., \& Cela, R. (2011). Optimization of pressurized liquid extraction and purification conditions for gas chromatography-mass spectrometry determination of UV filters in sludge. Journal of Chromatography A, 1218, 211-217. https://doi.org/10.1016/j. chroma.2010.11.028.

Nieto, A., Borrull, F., Marcé, R. M., \& Pocurull, E. (2009). Determination of personal care products in sewage sludge by pressurized liquid extraction and ultra high performance liquid chromatography-tandem mass spectrometry. Journal of Chromatography A, 1216, 5619-5625. https://doi. org/10.1016/j.chroma.2009.05.061.

Plagellat, C., Kupper, T., Furrer, R., de Alencastro, L. F., Grandjean, D., \& Tarradellas, J. (2006). Concentrations and specific loads of UV filters in sewage sludge origination from a monitoring network in Switzerland. Chemosphere, 62, 915-925. https://doi.org/10.1016/j.chemosphere.2005.05.024.

Poiger, T., Buser, H.-R., Balmer, M. E., Bergqvist, P.-A., \& Müller, M. D. (2004). Occurrence of UV filter compounds from sunscreens in surface waters: regional mass balance in two Swiss lakes. Chemosphere, 55, 951-963. https://doi. org/10.1016/j.chemosphere.2004.01.012.

Ramos, S., Homem, V., Alves, A., Santos L. (2016) A review of organic UV-filters in wastewater treatment plants. Environment International 86, 24-44. https://doi. org/10.1016/j.envint.2015.10.004

Rodil, R., Moeder, M., Altenburgr, R., \& Schmitt-Jansen, M. (2009). Photostability and phytotoxicity of sunscreen agents and their degradation mixtures in water. Analytical and Bioanalytical Chemistry, 395, 1513-1524. https://doi. org/10.1007/s00216-009-3113-1.

Román, I. P., Chisvert, A., \& Canals, A. (2011). Dispersive solidphase extraction based on oleic acid-coated magnetic nanoparticles followed by gas chromatography-mass spectrometry for UV-filter determination in water samples. Journal of Chromatography A, 1218, 2467-2475. https://doi. org/10.1016/j.chroma.2011.02.047.

Studziński, W., \& Gackowska, A. (2018). Evaluation of degradation efficiency of 2'-ethylhexyl 4-(dimethylamino)benzoate under the influence of oxidizing agents. Journal of Ecological Engineering, 19(4), 236-241. https://doi. org/10.12911/22998993/89665.

Studziński, W., Gackowska, A., Przybyłek, M., \& Gaca, J. (2017). Studies on the formation of formaldehyde during 2ethylhexyl 4-(dimethylamino)benzoate demethylation in the presence of reactive oxygen and chlorine species. Environmental Science and Pollution Research, 24, 80498061. https://doi.org/10.1007/s11356-017-8477-8.
Tröger, R., Klöckner, P., Ahrens, L., \& Wiberg, K. (2018). Micropollutants in drinking water from source to tap - method development and application of a multiresidue screening method. Science of the Total Environment, 627, 1404-1432. https://doi.org/10.1016/j.scitotenv.2018.01.277.

Tsui, M. M. P., Leung, H. W., Lam, P. K. S., \& Murphy, M. B. (2014a). Seasonal occurrence, removal efficiencies and preliminary risk assessment of multiple classes of organic UV filters in wastewater treatment plants. Water Research, 53, 58-67. https://doi.org/10.1016/j.watres.2014.01.014.

Tsui, M. M. P., Leung, H. W., Wai, T.-C., Yamashita, N., Taniyasu, S., Liu, W., Lam, P. K. S., \& Murphy, M. B. (2014b). Occurrence, distribution and ecological risk assessment of multiple classes of UV filters in surface waters from different countries. Water Research, 67, 55-65. https://doi. org/10.1016/j.watres.2014.09.013.

Tsui, M. M. P., Leung, H. W., Kwan, B. K. Y., Ng, K.-Y., Yamashita, N., Taniyasu, S., Lam, P. K. S., \& Murphy, M. B. (2015). Occurrence, distribution and ecological risk assessment of multiple classes of UV filters in marine sediments in Hong Kong and Japan. Journal of Hazardous Materials, 292, 180-187. https://doi.org/10.1016/j. jhazmat.2015.03.025.

Weiss, S., Jakobs, J., \& Reemtsma, T. (2006). Discharge of three benzotriazole corrosion inhibitors with municipal wastewater and improvements by membrane bioreactor treatment and ozonation. Environmental Science \& Technology, 40, 71937199. https://doi.org/10.1021/es061434i.

Wu, J.-W., Chen, H.-C., \& Ding, W.-H. (2013). Ultrasoundassisted dispersive liquid-liquid microextraction plus simultaneous silylation for rapid determination of salicylate and benzophenone-type ultraviolet filters in aqueous samples. Journal of Chromatography A, 1302, 20-27. https://doi. org/10.1016/j.chroma.2013.06.017.

Zhang, Z. F., Ren, N. Q., Li, Y. F., Kunisue, T., Gao, D. W., \& Kannan, K. (2011). Determination of benzotriazole and benzophenone UV filters in sediment and sewage sludge. Environmental Science \& Technology, 45, 3909-3916. https://doi.org/10.1021/es2004057.

Zhao, X., Ma, J., Ma, H., Gao, D., Sun, Y., \& Guo, C. (2018). Removal of polyacrylate in aqueous solution by activated sludge: characteristics and mechanisms. Journal of Cleaner Production, 178, 59-66. https://doi.org/10.1016/j. jclepro.2017.12.215.

Publisher's Note Springer Nature remains neutral with regard to jurisdictional claims in published maps and institutional affiliations. 